\title{
PENGEMBANGAN SISTEM INFORMASI ALUMNI BERBASIS WEB FAKULTAS SAINS DAN TEKNOLOGI UNIVERSITAS ISLAM NEGERI MAULANA MALIK IBRAHIM MALANG
}

\author{
M. Ainul Yaqin, A’la Syauqi, Faiz Afiani Rohma, Annisa Puspa Kirana \\ Jurusan Teknik Informatika
}

Fakultas Sains dan Teknologi, Universitas Islam Negeri Maulana Malik Ibrahim Malang

Kampus UIN, Jl. Gajayana No. 50 Malang, Telp. +62 341-558933, Fax. +62 341-558933

\begin{abstract}
Abstrak-Salah satu tolok ukur keberhasilan pendidikan di perguruan tinggi adalah jumlah dan kualitas lulusan yang dihasilkan. Hal ini dinyatakan dalam salah satu standar akreditasi yang manyatakan jumlah lulusan, evaluasi kinerja lulusan, studi pelacakan lulusan, waktu tunggu rata-rata untuk memperoleh pekerjaan pertama, dan prosentase lulusan yang bekerja di bidang yang sesuai dengan keahliannya.Fakultas Sains dan Teknologi UIN Maliki Malang saat ini sudah berusia lebih dari 5 tahun, dan sudah menghasilkan banyak lulusan. Dari sekian banyak jumlah lulusan tersebut banyak yang sudah terserap oleh lapangan kerja yang disediakan oleh berbagai pihak. Sayangnya informasi tersebut tidak didukung oleh data-data yang detil dan terdokumentasi, sehingga ketika pihak Fakultas Sains dan Teknologi UIN Maliki Malang membutuhkan informasi tersebut untuk suatu keperluan merasa kesulitan.Untuk mengatasi masalah-masalah tersebut, maka perlu dikembangkan sistem informasi alumni jurusan teknik informatika. Sistem informasi tersebut akan dikembangkan dengan program berbasis web. Sehingga software yang digunakan untuk pengembangan sistem informasi ini adalah PHP, My SQL, dreamweaver, dan beberapa software lainnya.
\end{abstract}

\section{PENDAHULUAN}

Secara terminologi, website adalah kumpulan dari halaman-halaman situs, yang biasanya terangkum dalam sebuah domain atau subdomain, yang tempatnya berada di dalam World Wide Web (WWW) di Internet. Sebuah halaman web adalah dokumen yang ditulis dalam format HTML (Hyper Text Markup Language), yang hampir selalu bisa diakses melalui HTTP, yaitu protokol yang menyampaikan informasi dari server website untuk ditampilkan kepada para pemakai melalui web browser. Semua publikasi dari website-website tersebut dapat membentuk sebuah jaringan informasi yang sangat besar.

Halaman-halaman dari website akan bisa diakses melalui sebuah URL yang biasa disebut Homepage. URL ini mengatur halaman-halaman situs untuk menjadi sebuah hirarki, meskipun, hyperlink-hyperlink yang ada di halaman tersebut mengatur para pembaca dan memberitahu mereka sususan keseluruhan dan bagaimana arus informasi ini berjalan.

Sistem informasi yang perlu dikembangkan untuk alumni jurusan teknik informatika adalah sistem informasi yang memerlukan jaringan yang sangat besar dimana data-data para alumni dapat terdokumentasi dan dapat diakses secara online oleh semua orang, terutama para alumni yang mungkin sudah tidak berada di daerah sekitar Malang lagi.

\section{PHP}

Pada awalnya PHP merupakan kependekan dari Personal Home Page (Situs Personal). PHP pertama kali dibuat oleh Rasmus Lerdorf pada tahun 1995. Pada waktu itu PHP masih bernama FI (Form Interpreted), yang wujudnya berupa sekumpulan script yang digunakan untuk mengolah data form dari web. 
Pada Juni 2004, Zend merilis PHP 5.0. Dalam versi ini, inti dari interpreter PHP mengalami perubahan besar. Versi ini juga memasukkan model pemrograman berorientasi objek ke dalam PHP untuk menjawab perkembangan bahasa pemrograman ke arah paradigma berorientasi objek.

Kelebihan PHP dari bahasa pemrograman lain :

a. Bahasa pemrograman PHP adalah sebuah bahasa script yang tidak melakukan sebuah kompilasi dalam penggunaanya.

b. Web Server yang mendukung PHP dapat ditemukan di mana-mana dari mulai apache, IIS, Lighttpd, nginx, hingga Xitami dengan konfigurasi yang relatif mudah.

c. Dalam sisi pengembangan lebih mudah, karena banyaknya milis milis dan developer yang siap membantu dalam pengembangan.

d. Dalam sisi pemahamanan, PHP adalah bahasa scripting yang paling mudah karena memiliki referensi yang banyak.

e. PHP adalah bahasa open source yang dapat digunakan di berbagai mesin (Linux, Unix, Macintosh, Windows) dan dapat dijalankan secara runtime melalui console serta juga dapat menjalankan perintahperintah system.

\section{MYSQL}

MySQL adalah sebuah perangkat lunak sistem manajemen basis data SQL (bahasa Inggris: database management system) atau DBMS yang multithread, multi-user, dengan sekitar 6 juta instalasi di seluruh dunia. MySQL AB membuat MySQL tersedia sebagai perangkat lunak gratis dibawah lisensi GNU General Public License (GPL), tetapi mereka juga menjual dibawah lisensi komersial untuk kasuskasus dimana penggunaannya tidak cocok dengan penggunaan GPL.
MySQL adalah Relational Database Management System (RDBMS) yang didistribusikan secara gratis dibawah lisensi GPL (General Public License). Dimana setiap orang bebas untuk menggunakan MySQL, namun tidak boleh dijadikan produk turunan yang bersifat komersial. MySQL sebenarnya merupakan turunan salah satu konsep utama dalam database sejak lama, yaitu SQL (Structured Query Language). MySQL memiliki beberapa keistimewaan, antara lain :

a. Portabilitas. MySQL dapat berjalan stabil pada berbagai sistem operasi seperti Windows, Linux, FreeBSD, Mac Os X Server, Solaris, Amiga, dan masih banyak lagi.

b. Open Source.MySQL didistribusikan secara open source, dibawah lisensi GPL sehingga dapat digunakan secara cuma-cuma.

c. 'Multiuser'. MySQL dapat digunakan oleh beberapa user dalam waktu yang bersamaan tanpa mengalami masalah atau konflik.

d. 'Performance tuning'. MySQL memiliki kecepatan yang menakjubkan dalam menangani query sederhana, dengan kata lain dapat memproses lebih banyak SQL per satuan waktu.

e. Jenis Kolom. MySQL memiliki tipe kolom yang sangat kompleks, seperti signed/unsigned integer, float, double, char, text, date, timestamp, dan lain-lain.

f.Perintah dan Fungsi. MySQL memiliki operator dan fungsi secara penuh yang mendukung perintah Select dan Where dalam perintah (query).

g. Keamanan. MySQL memiliki beberapa lapisan sekuritas seperti level subnetmask, nama host, dan izin akses user dengan sistem perizinan yang mendetail serta sandi terenkripsi.

h. Skalabilitas dan Pembatasan. 
MySQL mampu menangani basis data dalam skala besar, dengan jumlah rekaman (records) lebih dari 50 juta dan 60 ribu tabel serta 5 milyar baris. Selain itu batas indeks yang dapat ditampung mencapai 32 indeks pada tiap tabelnya.

i. Konektivitas. MySQL dapat melakukan koneksi dengan klien menggunakan protokol TCP/IP, Unix soket (UNIX), atau Named Pipes (NT).

j.Lokalisasi. MySQL dapat mendeteksi pesan kesalahan pada klien dengan menggunakan lebih dari dua puluh bahasa. Meski pun demikian, bahasa Indonesia belum termasuk di dalamnya.

k. Antar Muka. MySQL memiliki interface (antar muka) terhadap berbagai aplikasi dan bahasa pemrograman dengan menggunakan fungsi API (Application Programming Interface).

1. Klien dan Peralatan. MySQL dilengkapi dengan berbagai peralatan (tool)yang dapat digunakan untuk administrasi basis data, dan pada setiap peralatan yang ada disertakan petunjuk online.

m. Struktur tabel. MySQL memiliki struktur tabel yang lebih fleksibel dalam menangani ALTER TABLE, dibandingkan basis data lainnya semacam PostgreSQL ataupun Oracle.

\section{APACHE}

Server HTTP Apache atau Server Web/WWW Apache adalah server web yang dapat dijalankan di banyak sistem operasi (Unix, BSD, Linux, Microsoft Windows dan Novell Netware serta platform lainnya) yang berguna untuk melayani dan memfungsikan situs web. Protokol yang digunakan untuk melayani fasilitas web/www ini menggunakan HTTP.

Apache memiliki fitur-fitur canggih seperti pesan kesalahan yang dapat dikonfigur, autentikasi berbasis basis data dan lain-lain. Apache juga didukung oleh sejumlah antarmuka pengguna berbasis grafik (GUI) yang memungkinkan penanganan server menjadi mudah.

Apache merupakan perangkat lunak sumber terbuka dikembangkan oleh komunitas terbuka yang terdiri dari pengembang-pengembang dibawah naungan Apache Software Foundation.

\section{ANALISIS DAN PERANCANGAN SISTEM}

\section{- Analisa Sistem Saat Ini}

Fakultas Saintek UIN Maliki Malang belum mempunyai sistem yang baik untuk data mahasiswa yang telah lulus atau alumni. Sehingga, sistem yang ada perlu dikembangkan agar menjadi lebih efektif dan efisien.

Permasalahan yang muncul dalam pembuatan sistem ini adalah:

1.
istem tidak
terintegrasi
dan belum
terkomputeri
sasi
2.
DM yang
kurang
menguasai
penggunaan
sistem

\section{- Analisis Kebutuhan}

Tabel 1. Tabel Analisis Kebutuhan

\begin{tabular}{|l|l|}
\hline $\begin{array}{l}\text { Kebutuhan } \\
\text { Fungsional }\end{array}$ & \multicolumn{2}{l|}{ Kebutuhan non- } \\
Fungsional
\end{tabular}




\begin{tabular}{|l|l|}
\hline - Membuat halaman & untuk setiap jurusan. \\
user untuk penampilan & \\
dan pencarian data. & \\
2. Mengintegrasikan & \\
website alumni dengan & \\
Website UIN Maliki & \\
Malang agar lebih & \\
efektif dan efisien. & \\
3. Aplikasi dapat & \\
selesai dalam waktu satu & \\
bulan, sehingga dapat & \\
segera digunakan. & \\
\hline
\end{tabular}

\section{- Desain Proses}

Untuk memudahkan penggambaran suatu sistem yang ada atau sistem yang baru yang akan dikembangkan secara logika tanpa memperhatikan lingkungan fisik dimana data tersebut mengalir atau lingkungan fisik dimana data tersebut akan disimpan, maka kita menggunakan Diagram Arus Data atau Data Flow Diagram. Diagram alur data merupakan alat yang cukup populer sekarang, karena dapat menggambarkan arus data di dalam suatu sistem dengan terstruktur dan jelas, itulah sebabnya DAD merupakan alat bantu yang paling penting bagi seorang analis sistem.Berikut ini adalah desain proses dari Website Alumni Fakultas Sains dan Teknologi UIN Maulana Malik Ibrahim (Maliki) Malang:

\section{a. DFD level 0}

Data Flow Diagram level 0 adalah gambaran secara umum untuk mengidentifikasikan komponen-komponen yang ada pada sistem. Untuk lebih jelasnya dapat dilihat pada gambar berikut:

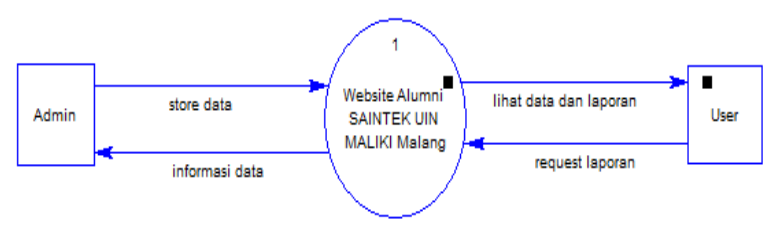

Gambar 1. DFD level 0

\section{b. DFD level 1}

Data Flow Diagram level 1 ini menjelaskan alur program secara keseluruhan yang ada pada aplikasi mulai dari pengidentifikasian user sampai pada proses yang ada pada website alumni.

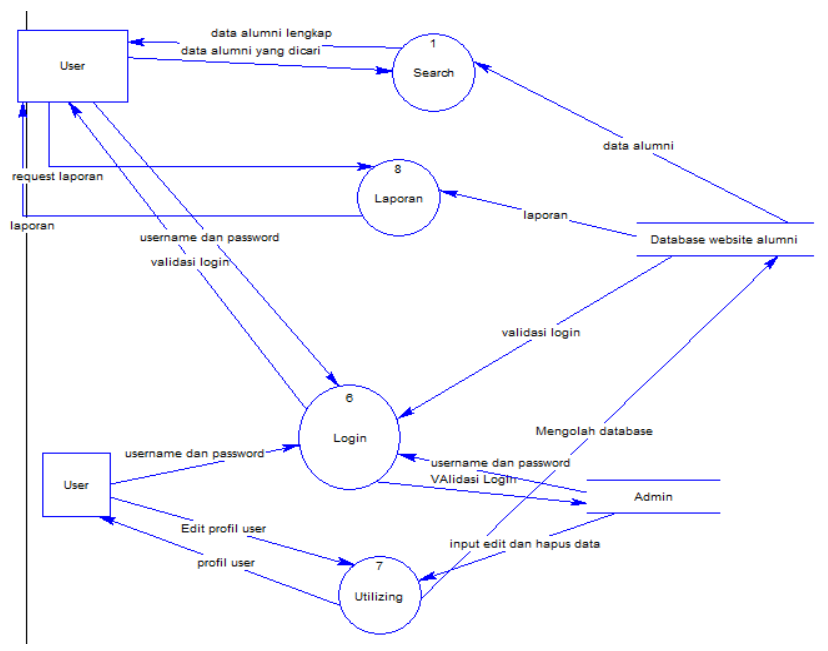

Gambar 2. DFD level 1

- Desain Database

Desain database adalah desain yang menggambarkan relasi antar tabel di dalam suatu database. Setiap tabel memiliki fungsi dan karakteristik tersendiri yang mampu melengkapi kebutuhan data atau menu yang ada di dalam tabel. Database yang bagus adalah database yang mampu dinormalisasi, dimana setiap tabelnya mampu berdiri sendiri.

Relasi-relasi yang terdapat di dalam database digambarkan dengan cermat di dalam Entity Relationship Diagram (ERD). 


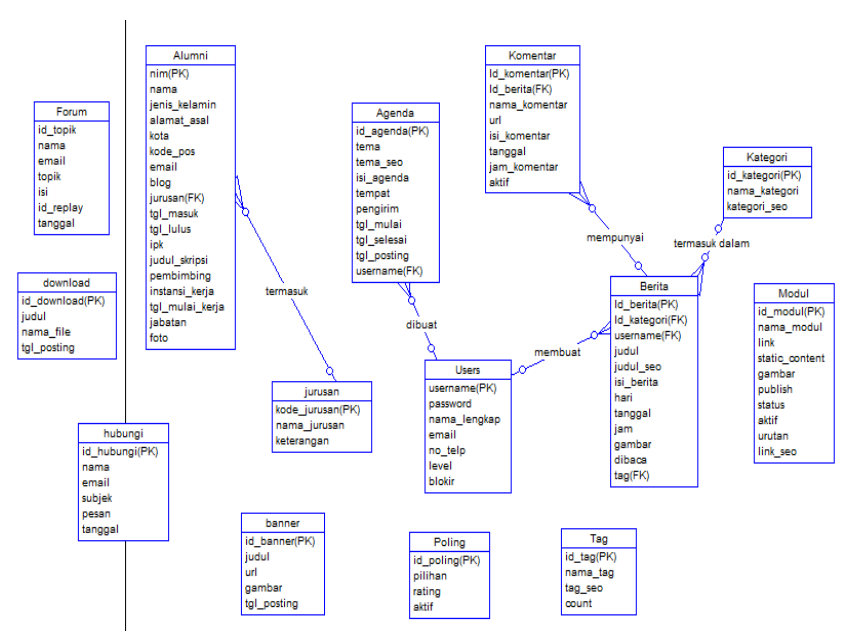

Gambar 3. Desain database

\section{HASIL DAN UJI COBA}

Perangkat keras yang digunakan untuk pengembangan sistem informasi berbasis web alumni jurusan Teknik Informatika UIN Maliki Malang adalah sebagai berikut:
a. Processor Intel Celeron M 1.60 $\mathrm{GHz}$
b. RAM $512 \mathrm{MB}$
c. Hard Disk $80 \mathrm{~GB}$
d. LCD 15.4" dengan resolusi $1280 \mathrm{x}$ 800 pixel
Adapun perangkat lunak yang digunakan adalah :
a. Sistem Operasi Windows Vista Home Premium
b. PHP 5.1.6
c. MySQL 5.0.24a
d. Adobe Dreamweaver cs3
e. Adobe Photoshop cs3
f. Power Designer

\section{Implementasi dan Interface}

a. Halaman Home User

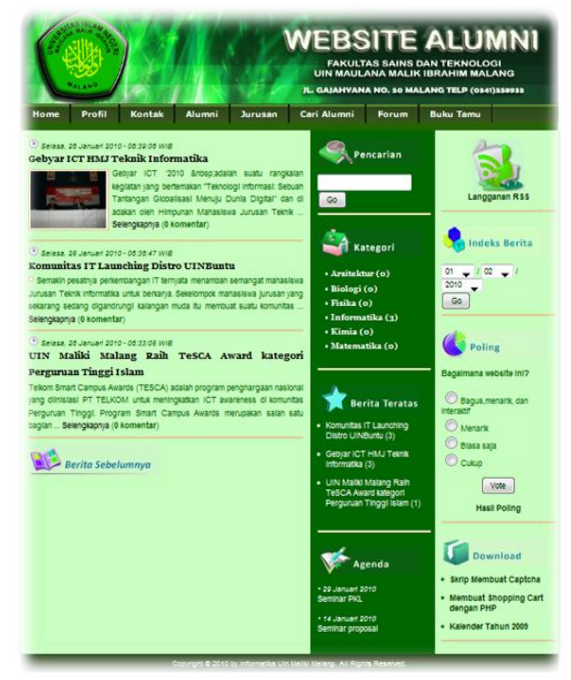

Gambar 4. Halaman Depan web alumni UIN Maliki Malang

Tampilan depan website alumni UIN Maliki Malangberwarna kalem (Green Glass), hal ini dipilih agar pengguna tidak cepat bosan dalam menjelajah website. Ketika pertama kali membuka website alumni, pengguna langsung dapat melihat berita terbaru yang telah ditulis oleh administrator, ataupun user yang telah terdaftar, penulis meletakkan beritadi halaman beranda website tujuannya agar pengguna tidak terlalu lama menjelajah website untuk mencari beritaterbaru. Tampilan utama juga menyediakan beberapa menu yang berhubungan dengan alumni. Menu-menu tersebut adalah sebagai berikut: alumni (menampilkan alumni yang terdaftar), cari alumni (digunakan untuk melakukan pencarian alumni), pendaftaran (untuk pendaftaran alumni).

b. Halaman Home Admin untuk para alumni yang telah login 


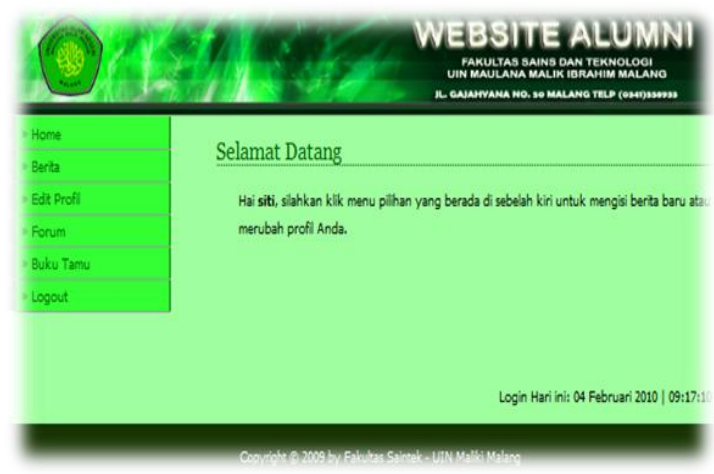

Gambar 5. Halaman home admin user yang terdaftar

Di halaman home ini, para alumni yang telah terdaftar dapat menambah, mengedit, ataupun menghapus keterangan yang ada di profil masing-masing. Mereka juga mempunyai hak untuk menambah berita dan mengisi buku tamu.

c. Halaman Home Super Administrator setelah login

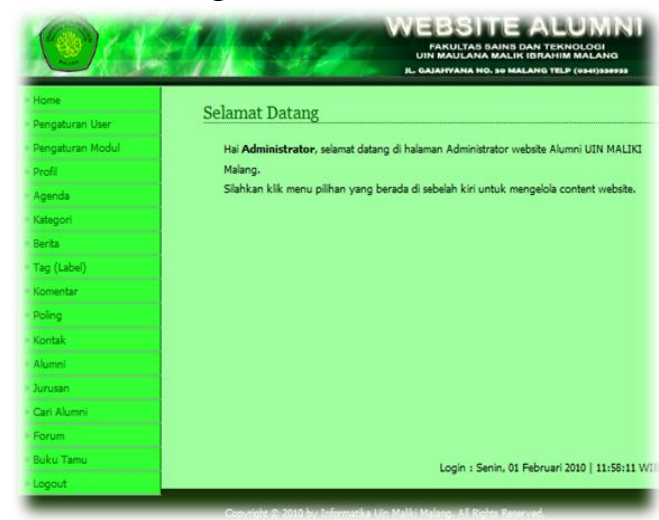

Gambar 6. Halaman Admin Home

Pada halaman home ini, super admin mempunyai hak untuk menambah, mengedit, dan menghapus modul yang ada pada website alumni. Modul-modul tersebut adalah untuk pengaturan user, pengaturan modul, profil, agenda, kategori, berita, tag (label), komentar, poling, kontak, alumni, jurusan, cari alumni, forum, dan buku tamu.

\section{KESIMPULAN}

Aplikasi Sistem Informasi Alumni berbasis web ini dapat digunakan untuk mendokumentasikan data-data alumni mahasiswa Fakultas Sains dan Teknologi.
Sistem ini dapat menghasilkan informasi keberadaan mahasiswa setelah menyelesaikan studinya.

Sistem Informasi Alumni ini dapat dikembangkan dan diaplikasikan bukan hanya untuk lingkup fakultas saja tetapi lingkup yang lebih luas lagi yaitu universitas. Aplikasi ini dapat dikembangkan/disempurnakan lagi menggunakan teknologi AJAX sehingga kelihatan lebih dinamis dan menarik.

\section{DAFTAR PUSTAKA}

Abdul Kadir, 2004. Dasar-dasar Pemrograman Web Dinamis dengan JSP. Yogyakarta: Andi

Abdul Kadir, 2009. Mastering Ajax dan PHP. Yogyakarta: Andi

Lukmanul Hakim, 2009. Trik Rahasia Master PHP. Yogyakarta: Lokomedia

Madcoms, 2009. Aplikasi Program PHP+MySQL untuk Membuat Web Interaktif. Yogyakarta: Andi

http://www.php.net/archive/2010.php\#id20 10-03-04-1, diakses tanggal: 5 April 2010, jam: 07.33

http://httpd.apache.org/, diakses tanggal: 5 Februari 2010, jam: 07.33

http://www.mysql.com/, diakses tanggal: 5 Februari 2010, jam: 07.33 